\title{
Psittacosis Causing Acute Respiratory Distress Syndrome (ARDS)
}

Tânia Freitas Raso ${ }^{*}$, Vivian Lindmayer Ferreira ${ }^{1}$, Bil Randerson Bassetti ${ }^{2}$, Jaques Sztajnbok ${ }^{2}$, Zarifa Khoury ${ }^{2}$, Rodrigo Delfino Nascimento ${ }^{2}$ and Marcos Vinicius da Silva ${ }^{2}$

${ }^{1}$ Faculdade de Medicina Veterinária e Zootecnia, Universidade de São Paulo, Brazil

${ }^{2}$ Instituto de Infectologia Emilio Ribas, São Paulo, Brazil

\begin{abstract}
Chlamydia psittaci is the causative agent of psittacosis. The illness varies from a mild disease to a fatal systemic illness. In recent years the role of $C$. psittaci causing atypical pneumonia has become more appreciated. Here we present a severe psittacosis case resulting in acute respiratory distress syndrome (ARDS) in a woman which had contact with a pet cockatiel. Chest computed tomography scan demonstrated extensive air-space disease interspersed by airbronchograms in the dependend portions of both lower lobes. Focal areas of consolidation were also observed in the middle and superior lobes. The diagnosis was suggested on the basis of epidemiologic criteria of exposure to birds and confirmed by a serological test revealing high titers of IgG by MIF assay. In these cases psittacosis should be considered in the differential diagnosis.
\end{abstract}

Keywords: Atypical pneumonia; Chlamydiosis; Pet birds; Zoonosis

\section{Introduction}

The acute respiratory distress syndrome (ARDS) is a major cause of acute respiratory failure. Therefore, early recognition of this syndrome and application of demonstrated therapeutic interventions are essential to change the natural course of this devastating entity [1]. Severe respiratory failure can be caused by atypical pathogens, including Chlamydia psittaci, the causative agent of human psittacosis [2]. Infection with $C$. psittaci usually occurs when a person inhales organisms that have been aerosolized from dried feces or respiratory tract secretions of infected birds. In humans, zoonotic transfer may result in subclinical infection, manifesting either as a 'flu-like' illness or as a potentially lethal pneumonia. With early diagnosis and appropriate treatment, patients presenting a case of psittacosis usually have a good prognosis [3]. On the other hand, delays in diagnosis and treatment may lead to severe complications, such as acute respiratory failure and even death [4-8]. In this report, we describe an unusual case of severe psittacosis related to pet bird exposure.

\section{Case History}

A 36 year old woman was admitted to the emergency room at the Instituto de Infectologia Emilio Ribas (IIER), with acute respiratory distress syndrome. The patient had been well until one week prior to her admission, when she had several episodes of diarrhea and vomiting, followed by a fever $\left(38-38.5^{\circ} \mathrm{C}\right)$ and fatigue (day 1 of symptoms). During this time she searched for medical care at another hospital and later being discharged with symptomatic treatment and a presumptive diagnosis of dengue. Four days later, she presented dry cough, dyspnea and chest pain; and a fever $\left(39^{\circ} \mathrm{C}\right)$ subsequently. Upon admission to IIER, day 7 after the onset of clinical signs, she reported no vomiting or diarrhea. She was acyanotic, with a temperature of $37.3^{\circ} \mathrm{C}$, blood pressure recorded at $131 \times 77 \mathrm{mmHg}$, pulse of 121 beats per minute, and a respiratory rate of 32 breaths per minute. Blood arterial gas saturation was $88 \%$ in room air conditions. The liver was enlarged and tender upon abdominal palpation ( $3.0 \mathrm{~cm}$ below the right costal margin). On auscultation, fine crackles were present on lower and middle lung fields. A chest computed tomography scan demonstrated extensive air-space disease interspersed by air-bronchograms in the dependend portions of both inferior lung lobes. Focal areas of consolidation were also observed in the middle and superior lobes (Figure 1). Laboratory tests showed abnormal liver function and C-reactive protein and leukocyte count of $11 \times 10^{3} \mathrm{cell} / \mathrm{mm}^{3}$ with left shift (Table 1). Urine and blood culture were negative. Serologic tests for HIV and Histoplasma capsulatum were also negative.

The patient was married and lived with her family in an urban area. There was no history of recent travels. No significant past medical history regarding infectious diseases, smoking, illicit drug use or exposure to suspected ill individuals was determined. The patient had been vaccinated for H1N1 the previous year. The only comorbidity reported was hypothyroidism, treated with conventional levothyroxine regimen.

The patient purchased a pet cockatiel (Nymphicus hollandicus) from a pet store three weeks earlier and reported close contact with the bird. About two weeks after the purchase, the bird started to refuse food and being hypoactive, which was followed by diarrhea. At this point, the bird was taken to a veterinarian but died soon afterwards. Necropsy and laboratorial analysis of the bird's biological samples were not conducted.

After hospital admission, the patient was immediately transferred to an intensive care unit and therapy was initiated with clarithromycin (500 mg twice a day), ceftriaxone (1 g twice a day) and amphotericin B ( $40 \mathrm{mg}$ once a day); with $50 \%$ oxygen administered by face mask. Serum sample was obtained by standard procedures and tested for specific $C$. psittaci IgG antibodies by microimmunofluorescence (MIF). The test was performed with a Chlamydia MIF IgG test (Focus Technologies, USA) according to the manufacturer's instructions. Anti-C. psittaci IgG titer was 1:1,024.

On the subsequent days (days 8-9) her clinical condition worsened, requiring respiratory support with continuous positive airway pressure (CPAP). On the tenth day of hospitalization, the patient began to display a stable respiratory condition. The days following, there was gradual improvement of the patient's clinical condition and laboratory

*Corresponding author:Tânia Freitas Raso, Professor, PhD, M.D. Faculdade de Medicina Veterinária e Zootecnia, FMVZ/USP, Departamento de Patologia, Faculdade de Medicina Veterinária e Zootecnia, Av. Prof Dr. Orlando Marques de Paiva, 87, Cidade Universitária "Armando de Salles Oliveira", São Paulo-SP, Brazil, Tel: 55-11-3091-1436; Fax: 55-113091-7829; E-mail: tfraso@usp.br

Received May 27, 2015; Accepted August 18, 2015; Published August 24, 2015

Citation: Raso TF, Ferreira VL, Bassetti BR, Sztajnbok J, Khoury Z, et al. (2015) Psittacosis Causing Acute Respiratory Distress Syndrome (ARDS). J Pulm Respir Med 5: 283. doi:10.4172/2161-105X.1000283

Copyright: ( 2015 Raso TF, et al. This is an open-access article distributed under the terms of the Creative Commons Attribution License, which permits unrestricted use, distribution, and reproduction in any medium, provided the original author and source are credited. 


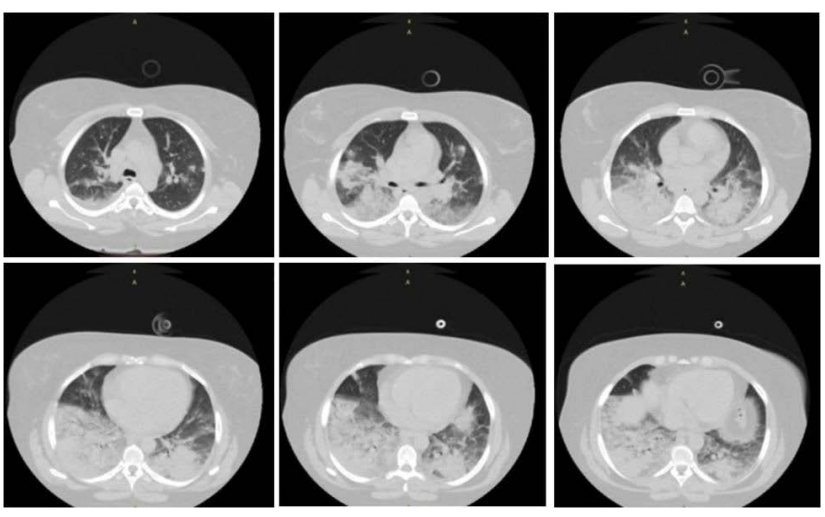

Figure 1: Computed tomography scan (A-F). Confluent and asymmetric areas of frank air-space consolidation mixed with alveolar and groundglass infiltrates compromising the lower lobes, interspersed by thin aerobroncograms.

\begin{tabular}{|c|c|c|c|c|}
\hline & Day 7 & Day 8 & Day 14 & Day 22 \\
\hline \multicolumn{5}{|c|}{ Gasometry } \\
\hline $\mathrm{pH}(7.3-7.4)$ & 7.51 & 7.43 & 7.4 & 7.52 \\
\hline $\mathrm{pCO}_{2}(41-51 \mathrm{mmHg})$ & 27 & 34 & 32 & 35 \\
\hline $\mathrm{pO}_{2}(80-105 \mathrm{mmHg})$ & 58 & 101 & 70 & 131 \\
\hline $\mathrm{HCO}_{3}(23-28 \mathrm{mmol} / \mathrm{L})$ & 22 & 22 & 24.9 & 29 \\
\hline $\mathrm{BE}$ ecf $(-2-3 \mathrm{mmol} / \mathrm{L})$ & -1 & -2 & 2 & 6 \\
\hline $\mathrm{FiO}_{2}(\%)$ & $21 \%$ & $21 \%$ & $50 \%$ & - \\
\hline Sat. $\mathrm{O}_{2}(95-98 \%)$ & $92 \%^{\dagger}$ & $98 \%$ & $95 \%$ & $99 \%$ \\
\hline \multicolumn{5}{|c|}{ Leukogram } \\
\hline $\begin{array}{c}\text { Total leukocytes } \\
\left(4.1-11.2 \times 10^{3} / \mathrm{mm}^{3}\right)\end{array}$ & 11 & 6.7 & 10.4 & 8.7 \\
\hline Neutrophils (39.9-73\%) & $9240(84 \%)$ & $\begin{array}{c}4917.8 \\
(73.4 \%)\end{array}$ & $8944(86 \%)$ & $\begin{array}{l}5324.4 \\
(61.2 \%)\end{array}$ \\
\hline Lymphocytes (20-45\%) & $660(6 \%)$ & $911.2(13.6 \%)$ & $728(7 \%)$ & $\begin{array}{c}2401.2 \\
(27.6 \%)\end{array}$ \\
\hline Monocytes (2-12\%) & $660(6 \%)$ & $435.5(6.5 \%)$ & $312(3 \%)$ & $\begin{array}{l}765.6 \\
(8.8 \%)\end{array}$ \\
\hline Basophils $(0.3-2 \%)$ & 0 & $20.1(0.3 \%)$ & $104(1 \%)$ & $52.2(0.6 \%)$ \\
\hline Eosinophils $(0.8-6 \%)$ & 0 & $80.4(1.2 \%)$ & $104(1 \%)$ & $\begin{array}{l}156.6 \\
(1.8 \%)\end{array}$ \\
\hline Band forms & $330(3 \%)$ & $335(5 \%)$ & $208(2 \%)$ & 0 \\
\hline Metamyelocytes & $110(1 \%)$ & 0 & 0 & 0 \\
\hline \multicolumn{5}{|c|}{ Liver function tests } \\
\hline ALP (65-300 IU/L) & 836 & 740 & 487 & - \\
\hline yGT (11-50 IU/L) & 317 & - & 281 & 147 \\
\hline AST (0-38 IU/L) & 101 & 84 & 24 & 17 \\
\hline ALT (0-41 IU/L) & 108 & 93 & 120 & 43 \\
\hline $\begin{array}{l}\text { C-reactive protein (0-5 } \\
\mathrm{mg} / \mathrm{L})\end{array}$ & 295.5 & 292.7 & 14.8 & - \\
\hline
\end{tabular}

$+88 \%$ in air room. Abbreviations: $\mathrm{pH}$ : potential of hydrogen; $\mathrm{pCO}_{2}$ : partial pressure of carbon dioxide; $\mathrm{pO}_{2}$ : Partial Pressure of Oxygen; $\mathrm{HCO}_{3}$ : Bicarbonate $\mathrm{BE}$ ecf: Base Excess in the Extracellular Fluid Compartment; $\mathrm{FiO}_{2}$ : Fraction of Inspired Oxygen; Sat. $\mathrm{O}_{2}$ : Oxygen Saturation; ALP: Alkaline Phosphatase; yGT: Gamma-Glutamyl Transpeptidase; AST: Aspartate Aminotransferase; ALT: Alanine Aminotransferase.

Table 1: Laboratory tests performed on patient's admission (day 7) to the day 22 from the initial symptoms of psittacosis.

exams (Table 1), but assisted ventilation was still required, with $50 \%$ oxygen on most occasions, until day 22 of hospitalization. Altogether, the patient stayed in the intensive care unit for 10 days and another 14 days in infirmary. Antibiotic therapy was performed with clarithromycin $(500 \mathrm{mg}$ twice a day) for 24 days and with ceftriaxone for 14 days ( $1 \mathrm{~g}$ twice daily).
The case was reported to public health authorities, which conducted an epidemiological surveillance tracking the source of infection back to the pet shop where the cockatiel was purchased. At the store, dropping samples were taken from nine birds and sent to a private laboratory for molecular analysis. C. psittaci's DNA was detected in 55\% (5/9) of the bird samples.

\section{Discussion}

According to the Centers for Disease Control and Prevention (CDC) in USA, from 2005 to 2009, 66 human cases of psittacosis were reported [3]. Nevertheless, these numbers are probably underestimated, since milder cases may not seek for medical attention and physicians are not always able to obtain a solid history of bird contact, which is a valuable clue to the diagnosis, as exposure to birds is reported in $85 \%$ of psittacosis cases [9]. Additionally, even when clinical psittacosis is suspected, diagnosis confirmation is still challenging. The most common confirmatory test is a rising titer to $C$. psittaci in paired sera with a microimmunofluorescence test. Most diagnostic difficulties are related to cross-reactivity with other Chlamydia spp. infecting humans as well as the frequent combination of empirical therapy for community-acquired pneumonia, which may blunt the antibody response to C. psittaci $[3,10]$.

Therefore, impact of C. psittaci infections on human health is difficult to evaluate. Before antimicrobial agents were available, $15 \%$ to $20 \%$ of humans with C. psittaci infection died. Despite the fact that mortality has been decreasing since the advent of antibiotics [3], prompt diagnosis and treatment of suspected cases is paramount in preventing fatal outcomes.

In the present report, the patient presented a severe respiratory failure with chest computed tomography scan findings nonspecific for lung air-space disease and extrapulmonary findings related to the liver dysfunction. These features are related to most severe forms of psittacosis [4-8,11], although have also been observed in other atypical pneumonias [2]. Since no other specific features were found at clinical presentation, a useful way to broaden the diagnosis scope is to review environmental exposure; which in this case, disclosed contact with a sick cockatiel. Consequently, suspicion of psittacosis was raised and patient's serum sample evaluated by means of MIF revelling IgG anti- $C$. psittaci titre of 1,024 .

Even with a single serum sample evaluation, the early diagnosis of psittacosis was essential for immediate epidemiologic investigations. Public health authorities reached the pet shop were the patient's bird had been purchased and took appropriated measures to avoid further cases. In addition, corroborates to our patients diagnosis confirmation since epidemiologic link to the source of infection was established and convincing evidence was obtained through the molecular detection of C. psittaci from the infected birds.

Psittacosis presenting as severe respiratory insufficiency is not usual, still diagnostic delay can be an important factor with respect to outcome $[4,9,10]$. Campaigns to raise awareness among professional health care workers and the general public to increase the degree of attentiveness to human psittacosis are needed.

\section{Acknowledgement}

We thank Dr. Alessandra C.G. Pellini and her team from the Central Epidemiological Surveillance (CVE, SES, São Paulo, Brazil) for the epidemiological investigation assistance.

\section{Compliance with Ethics Guidelines}

All procedures followed were in accordance with the ethical standards of 
Citation: Raso TF, Ferreira VL, Bassetti BR, Sztajnbok J, Khoury Z, et al. (2015) Psittacosis Causing Acute Respiratory Distress Syndrome (ARDS). J Pulm Respir Med 5: 283. doi:10.4172/2161-105X.1000283

the responsible committee on human experimentation (institutional and national) and with the Helsinki Declaration of 1975, as revised in 2000 and 2008. Informed consent was obtained from all patients for being included in the study. All institutional and national guidelines for the care of animals were followed.

\section{Financial Support}

sponsorship for this study was provided by FAPESP (no. 2012/25043-1; 2012/25067-8).

\section{References}

1. Modrykamien AM, Gupta $P(2015)$ The acute respiratory distress syndrome. Proc (Bayl Univ Med Cent) 28: 163-171.

2. Cunha BA (2006) The atypical pneumonias: clinical diagnosis and importance. Clin Microbiol Infect 12 Suppl 3: 12-24.

3. National Association of State Public Health Veterinarians (2010) Compendium of Measures To Control Chlamydophila psittaci Infection Among Humans (Psittacosis) and Pet Birds (Avian Chlamydiosis).

4. Verweij PE, Meis JF, Eijk R, Melchers WJ, Galama JM (1995) Severe human psittacosis requiring artificial ventilation: case report and review. Clin Infect Dis

$$
\text { 20: } 440-442 .
$$

5. Petrovay F, Balla E (2008) Two fatal cases of psittacosis caused by Chlamydophila psittaci. J Med Microbiol 57: 1296-1298.

6. Soni R, Seale JP, Young IH (1999) Fulminant psittacosis requiring mechanical ventilation and demonstrating serological cross-reactivity between Legionella longbeachae and Chlamydia psittaci. Respirology 4: 203-205.

7. Kovácová E, Majtán J, Botek R, Bokor T, Blaskovicová H, et al. (2007) A fatal case of psittacosis in Slovakia, January 2006. Euro Surveill 12: E070802.

8. Heddema ER, van Hannen EJ, Duim B, de Jongh BM, Kaan JA, et al. (2006) An outbreak of psittacosis due to Chlamydophila psittaci genotype $A$ in a veterinary teaching hospital. J Med Microbiol 55: 1571-1575.

9. Yung AP, Grayson ML (1988) Psittacosis--a review of 135 cases. Med J Aust 148: 228-233.

10. Beeckman DS, Vanrompay DC (2009) Zoonotic Chlamydophila psittaci infections from a clinical perspective. Clin Microbiol Infect 15: 11-17.

11. Ciftçi B, Güler ZM, Aydoğdu M, Konur O, Erdoğan Y (2008) Familial outbreak of psittacosis as the first Chlamydia psittaci infection reported from Turkey. Tuberk Toraks 56: 215-220. 